\title{
Splenic Marginal Zone Lymphoma with Acquired von Willebrand Syndrome Diagnosed via Splenic Bleeding
}

\author{
Yukiko Komeno ${ }^{1}$, Naoki Shibuya ${ }^{1}$, Hideki Uryu ${ }^{1}$, Haruki Yamada ${ }^{2}$, Takeo Toda ${ }^{3}$, \\ Masayuki Shibasaki ${ }^{3}$, Shinji Kunishima ${ }^{4}$, Kuniko Iihara ${ }^{5}$ and Tomiko Ryu ${ }^{1}$
}

\begin{abstract}
An 85-year-old woman underwent emergent splenectomy due to left abdominal pain and active bleeding in a massively enlarged spleen. The histological diagnosis was splenic marginal zone lymphoma (SMZL). A prolonged activated partial thromboplastin time (APTT) was noted, and additional tests led to the diagnosis of type 2A-like acquired von Willebrand syndrome (AVWS). An APTT cross mixing test ruled out the presence of inhibitors. She received eight courses of rituximab monotherapy. The coagulation data showed no improvement, possibly because the lymphoma showed a poor response to the treatment. AVWS rarely causes bleeding in solid organs. This is the first case of SMZL with AVWS diagnosed via splenic bleeding.
\end{abstract}

Key words: splenic marginal zone lymphoma (SMZL), splenic bleeding, acquired von Willebrand syndrome (AVWS), rituximab

(Intern Med 56: 557-562, 2017)

(DOI: 10.2169/internalmedicine.56.7258)

\section{Introduction}

Splenic marginal zone lymphoma (SMZL) is a rare lowgrade B-cell non-Hodgkin's lymphoma accounting for less than $2 \%$ of lymphoid neoplasms $(1,2)$. It mainly affects elderly patients with a median age of 65 years at diagnosis without gender predilection. It mainly involves the spleen, splenic hilar lymph nodes, bone marrow (BM), and occasionally the peripheral blood (PB) but not the peripheral lymph nodes. The diagnosis is based on the combination of clinical findings, BM histology, morphology, and immunophenotyping of the $\mathrm{PB}$, and when available, the histology of the excised spleen. Patients generally present with palpable splenomegaly. About one-third of patients have a small monoclonal serum protein ("M protein"). Due to slow progression, the "watch-and-wait" strategy is reserved for asymptomatic patients. For symptomatic patients with B symptoms, bulky or symptomatic splenomegaly, cytopenias, or autoimmune manifestations, treatments such as splenec- tomy and rituximab with/without chemotherapy have provided favorable outcomes. Antiviral therapy is applied to SMZL patients with coexistent hepatitis $\mathrm{C}$ virus infection $(2,3)$.

von Willebrand factor (VWF) is coagulation-related protein $(4,5)$. It binds to subendothelial collagen and platelet glycoprotein (GP) Ib/IX/V to support platelet adhesion. It also protects coagulation factor VIII from degradation in the circulation. von Willebrand disease (VWD) is caused by mutations in the VWF gene that result in deficiency or defects of VWF and manifests as a bleeding tendency characterized by prolonged activated partial thromboplastin time (APTT) and low factor VIII activity (5). Acquired von Willebrand syndrome (AVWS) is similar to VWD with regard to the clinical and laboratory parameters but is found in patients without a history of bleeding problems or family history $(6,7)$. The etiology of AVWS is varied and includes benign monoclonal gammopathy, lymphoproliferative diseases (multiple myeloma, Waldenström macroglobulinemia, chronic lymphocytic leukemia/small lymphocytic lymphoma,

\footnotetext{
${ }^{1}$ Department of Hematology, Japan Community Healthcare Organization (JCHO) Tokyo Yamate Medical Center, Japan, ${ }^{2}$ Department of Gastroenterology, JCHO Tokyo Yamate Medical Center, Japan, ${ }^{3}$ Department of Surgery, JCHO Tokyo Yamate Medical Center, Japan, ${ }^{4}$ Clinical Research Center, Nagoya Medical Center, National Hospital Center, Japan and ${ }^{5}$ Department of Pathology, JCHO Tokyo Yamate Medical Center, Japan

Received for publication February 10, 2016; Accepted for publication June 30, 2016

Correspondence to Dr. Yukiko Komeno, ykomeno-tky@umin.ac.jp
} 
non-Hodgkin's lymphoma, and hairy cell leukemia), autoimmune diseases, cardiovascular disorders, hypothyroidism, among others $(6,7)$.

We herein report a rare case of SMZL associated with AVWS diagnosed via splenic bleeding.

\section{Polymerase chain reaction (PCR) and sequencing of complementarity determining region-3 (CDR-3)}

Genomic DNA was extracted from paraffin-embedded tissues using a QIAamp DNA FFPE Tissue kit (Qiagen, Valencia, CA, USA). The CDR-3 region was amplified by nested PCR using the forward primer VH26 and reverse primers JH (for first PCR) and VLJH (for second PCR). The PCR products were purified using ExoSAP-IT (Affymetrix, Santa Clara, CA, USA). Cycle sequencing reaction was performed using the BigDye Terminator v1.1 Cycle Sequencing Kit (Applied Biosystems, Carlsbad, CA, USA). The products were purified using the BigDye XTerminator Purification Kit (Applied Biosystems) and then sequenced using a 3130xl Genetic Analyzer (Applied Biosystems) and primers (VH26 and VLJH). The detailed protocols are available on request.

\section{Immunofluorescence staining}

Cryostat sections of the patient's spleen and bone marrow were fixed with acetone and stained with anti-CD20 antibody (L26; Nichirei, Tokyo, Japan), anti-CD42b antibody (HPL7) (8) or anti VWF antibody (F8/86; Nichirei) and then reacted with Alexa 488-labeled anti-mouse IgG (green; Invitrogen, Carlsbad, CA, USA). The nucleus was counterstained with DAPI (blue). The stained slides were examined under a BX50 fluorescence microscope using DP Manager software (Olympus, Tokyo, Japan).

\section{Case Report}

In September 2007, a 78-year-old woman underwent surgery for appendicitis. Computed tomography (CT) of the abdomen revealed a swollen appendix, marked splenomegaly, and multiple mesenteric lymphadenopathies up to $5 \mathrm{~mm}$ in size. The paraaortic lymph nodes were not swollen. The liver function test findings were normal. She lacked superficial lymphadenopathy. In 2013, her splenomegaly was worsened on a follow-up CT scan.

At the end of December 2014, the patient was referred to the emergency room due to left upper abdominal pain. A blood test showed anemia, normal leukocyte and platelet counts, and a normal activated partial thromboplastin time (APTT) of 37.3 sec. Dynamic CT revealed even larger splenomegaly with active bleeding and multiple intraabdominal lymph nodes (mesenteric and paraarortic) that were increased in number and size compared to those in 2007 (Fig. 1A). Emergency splenectomy was performed. Given that hemostasis was difficult during surgery, 4 units of freshly frozen plasma (FFP) were transfused. Since the coagulation data after surgery showed a prolonged APTT
(108.2 sec), an additional 4 units of FFP were transfused. The APTT the following day was $51.8 \mathrm{sec}$. The excised spleen was fragile, $23 \times 15 \times 6 \mathrm{~cm}$ in size, and weighed 1,200 g. Histology revealed massive bleeding in the form of peliosis (Fig. 1B). In addition, there were clusters of atypical lymphocytes (Fig. 1B, inset). PCR amplification of CDR-3 using the splenic tissues from two separate locations produced monoclonal bands of the same size (data not shown), suggesting a diagnosis of B-cell lymphoma. The EBER in situ hybridization (EBER-ISH) findings were negative. She was referred to the Department of Hematology (Table 1).

For a further cytological examination of the lymphoma, additional intraabdominal lymph node biopsy was performed. A bleeding tendency was also noted during the surgery. CT after the surgery revealed a hematoma under the surgical wound (data not shown). The pathological findings showed monotonous growth of atypical lymphocytes similar to that in the excised spleen (Fig. 1C). Some cells showed plasma cell-like differentiation with distended or multiple nuclei. Immunohistochemistry revealed the cells to be CD10 (-), CD20 (+), CD79a dim, CD3 (-), CD5 (-), CD23 (-), $\mathrm{Bcl} 2(+)$, and Bcl6 (-) with a low Ki67 index. The flow cytometry findings were CD45 (+), CD19 (+), CD20 (+), IgM $(-)$, and $\operatorname{Ig} \kappa(+)$. The karyotype was normal, although only two cells could be analyzed. Immunoglobulin heavy chain JH recombination was detected by Southern blotting (data not shown). The EBER-ISH findings were negative. These data and the clinical history of splenomegaly exacerbating over decades led to the diagnosis of splenic marginal zone lymphoma. The PCR products of CDR-3 using tissue from the spleen and a lymph node were of the same size, and their sequences matched perfectly, indicating that the spleen and lymph nodes had lymphoma cells of the same origin (Fig. 1D). A protein analysis revealed serum monoclonal paraprotein ( $\operatorname{IgG}$ ) and urine Bence Jones protein $\kappa$-type (data not shown). Biopsy of the gastric mucosa and bone marrow aspiration/biopsy revealed the invasion of lymphoma cells (Fig. 2A and B and data not shown). In the stomach, no lymphoepithelial lesions were found. Serum antibody against Helicobacter pylori was negative. Intestinal invasion was also suspected by colonoscopy (Fig. 2C). CT showed left pleural effusion and atelectasis of the left lower lobe, suggesting pleural infiltration of lymphoma (Fig. 2D) and multiple intraabdominal lymphadenopathies (Fig. 2E). As she had night sweats and body weight loss, the clinical stage was judged to be IV B.

After splenectomy, a coagulation test consistently showed a prolonged APTT (Table 2). A detailed analysis revealed decreased factor VIII activity (21\%), VWF activity determined as ristocetin cofactor activity $(\mathrm{RCo})<6 \%$, and VWF antigen (Ag) 20\%. The RCo/Ag ratio was $<0.3$. Platelet aggregation induced by ristocetin was decreased, while aggregation induced by $\mathrm{ADP}$ and collagen was normal (Fig. 3A-C). A VWF multimer assay showed an absence of large- and medium-sized multimers, similar to type $2 \mathrm{~A}$ VWD (Fig. 3D). A cross-mixing test with normal plasma 

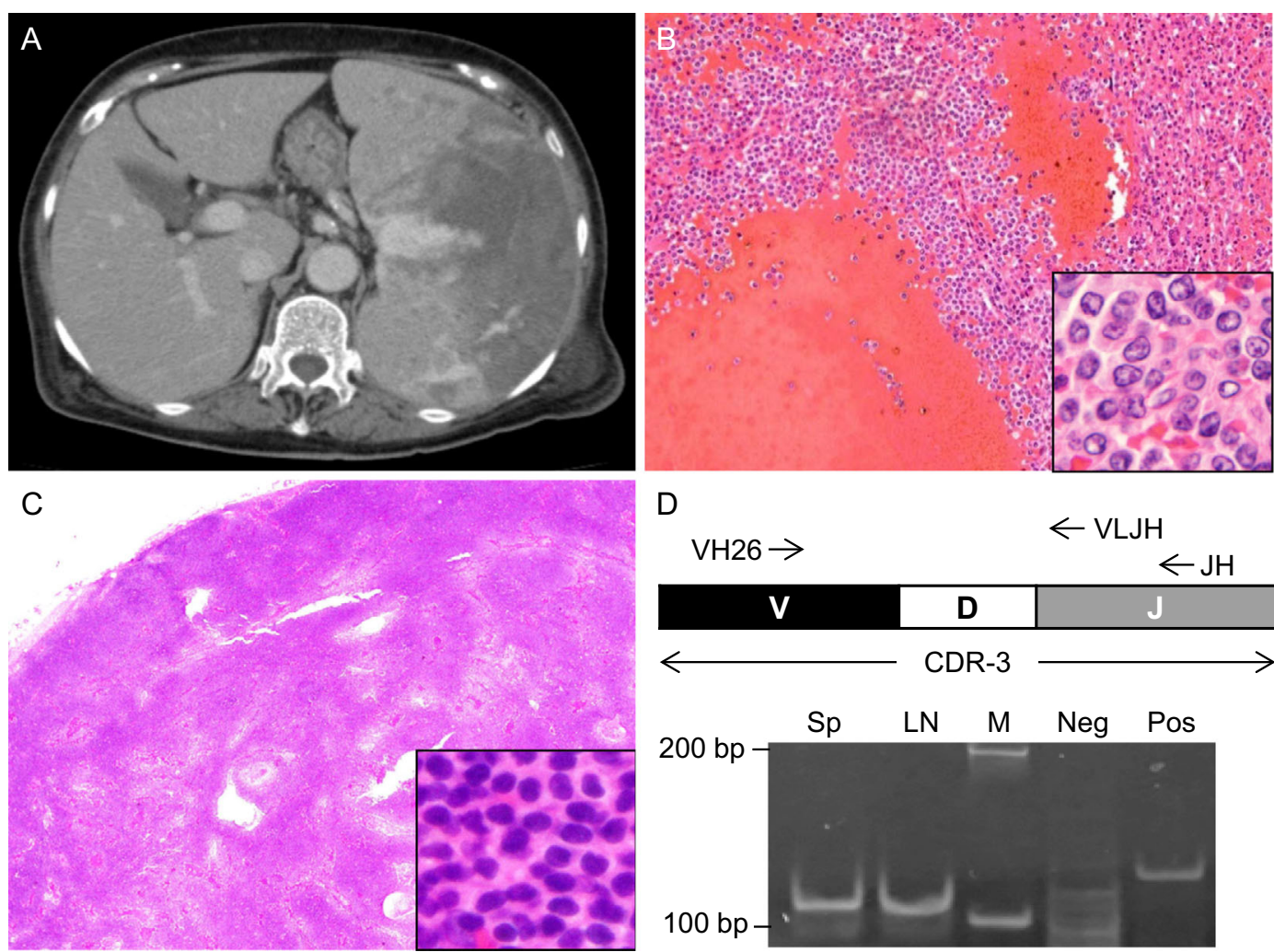

Figure 1. Splenic bleeding of splenic marginal zone lymphoma (SMZL). (A) A dynamic CT scan of the abdomen on admission. (B) Histology of the excised spleen. Hematoxylin and Eosin (H\&E) staining. Magnification, $\times 100$, inset $\times 1,000$. (C) Histology of the excised lymph node. H\&E staining. Magnification, $\times 20$. Inset, $\times 400$. (D) PCR amplification of complementarity determining region-3 (CDR3). The spleen (Sp) and lymph node (LN) lanes show monoclonal bands of the same size. VH26, forward primer. VLJH, reverse primer for second PCR. JH, reverse primer for first PCR. M, size marker. Neg, negative control. Pos, positive control.

Table 1. Laboratory Data on Referral to the Department of Hematology.

\begin{tabular}{|c|c|c|c|c|c|c|c|c|c|c|c|}
\hline & & Unit & Range & & & Unit & Range & & & Unit & Range \\
\hline WBC & 15,690 & $/ \mu \mathrm{L}$ & $3,500-9,000$ & Hemoglobin & 8.8 & $\mathrm{~g} / \mathrm{dL}$ & $12.0-16.0$ & BUN & 9.0 & $\mathrm{mg} / \mathrm{dL}$ & $8-20$ \\
\hline Monocytes & 8.0 & $\%$ & $2.0-11.0$ & $\mathrm{MCV}$ & 100.8 & $\mathrm{fL}$ & $80.0-100.0$ & Creatinine & $\underline{0.4}$ & $\mathrm{mg} / \mathrm{dL}$ & $0.5-0.9$ \\
\hline Lymphocytes & 17.5 & $\%$ & $19.0-49.0$ & Reticulocytes & 11.8 & $\times 10^{4} / \mu \mathrm{L}$ & & $\mathrm{Na}$ & 139 & $\mathrm{mEq} / \mathrm{L}$ & $135-145$ \\
\hline Basophils & 0.5 & $\%$ & $0.0-3.0$ & Platelets & 44.7 & $\times 10^{4} / \mu \mathrm{L}$ & $12.0-36.0$ & K & 4.3 & $\mathrm{mEq} / \mathrm{L}$ & $3.4-5.0$ \\
\hline Eosinophils & 2.0 & $\%$ & $0.0-5.0$ & Total protein & $\overline{6.5}$ & $\mathrm{~g} / \mathrm{dL}$ & $6.5-8.0$ & $\mathrm{Cl}$ & 105 & $\mathrm{mEq} / \mathrm{L}$ & $98-108$ \\
\hline Band & 0.5 & $\%$ & $0.0-7.0$ & Albumin & 2.6 & $\mathrm{~g} / \mathrm{dL}$ & $3.9-4.9$ & Blood sugar & 103 & $\mathrm{mg} / \mathrm{dL}$ & $70-107$ \\
\hline Segmented & 66.0 & $\%$ & $37.0-65.0$ & AST & $\overline{16}$ & $\mathrm{IU} / \mathrm{L}$ & $10-33$ & CRP & 0.2 & $\mathrm{mg} / \mathrm{dL}$ & $0.0-0.4$ \\
\hline Metamyelocytes & $\overline{0.5}$ & $\%$ & Not detectable & ALT & 8 & $\mathrm{IU} / \mathrm{L}$ & $4-30$ & IgG & $\underline{2,205}$ & $\mathrm{mg} / \mathrm{dL}$ & $870-1,700$ \\
\hline Myelocytes & $\overline{5.0}$ & $\%$ & Not detectable & LDH & $\underline{343}$ & $\mathrm{IU} / \mathrm{L}$ & $100-230$ & $\operatorname{Ig} \mathrm{A}$ & $\overline{240}$ & $\mathrm{mg} / \mathrm{dL}$ & $110-410$ \\
\hline Promyelocytes & 0.0 & $\%$ & Not detectable & ALP & 179 & $\mathrm{IU} / \mathrm{L}$ & $100-328$ & IgM & $\underline{20}$ & $\mathrm{mg} / \mathrm{dL}$ & $46-260$ \\
\hline Blasts & 0.0 & $\%$ & Not detectable & $\gamma$-GTP & 23 & IU/L & $7-34$ & $\kappa / \lambda$ ratio & 2.37 & & $0.26-1.65$ \\
\hline $\mathrm{RBC}$ & 264 & $\times 10^{4} / \mu \mathrm{L}$ & $380-480$ & Bilirubin & 0.4 & $\mathrm{mg} / \mathrm{dL}$ & $0.2-1.2$ & sIL-2R & 1590 & $\mathrm{U} / \mathrm{mL}$ & $145-519$ \\
\hline
\end{tabular}

Underlines show the values outside the reference ranges. ALP: alkaline phosphatase, ALT: alanine aminotransferase, AST: aspartate aminotransferase, BUN: blood urea nitrogen, CRP: C-reactive protein, $\gamma$-GTP: gamma-glutamyl transferase, $\kappa / \lambda$ ratio: immunoglobulin light chain $\kappa / \lambda$ ratio, LDH: lactate dehydrogenase, MCV: mean corpuscular volume, RBC: red blood cells, sIL-2R: soluble interleukin-2 receptor

compensated the VWF activity to $33 \%$ ( $0 \mathrm{~h}$ incubation) and $39 \%$ ( $2 \mathrm{~h}$ incubation), ruling out the presence of anti-VWF inhibitors (Table 2).

She had no family history of a bleeding tendency. She had had three deliveries without coagulopathy. She underwent appendectomy without complication in 2007. In 2014, however, she had intractable bleeding after a dental procedure. She had also noticed multiple areas of ecchymosis in recent years.
To treat her lymphoma, rituximab monotherapy was chosen, since she refused to receive conventional chemotherapy. Rituximab $375 \mathrm{mg} / \mathrm{m}^{2}$ was administered every other week (instead of every week for the patient's convenience) for 8 sessions. CT after 4 courses showed the disappearance of the left pulmonary effusion and atelectasis and shrinkage of the lymphadenopathy. Soluble interleukin-2 receptor (sIL2R) levels continuously decreased from 1,590 U/mL (before treatment) to $788 \mathrm{U} / \mathrm{mL}$ (after 6 courses). Intraabdominal 

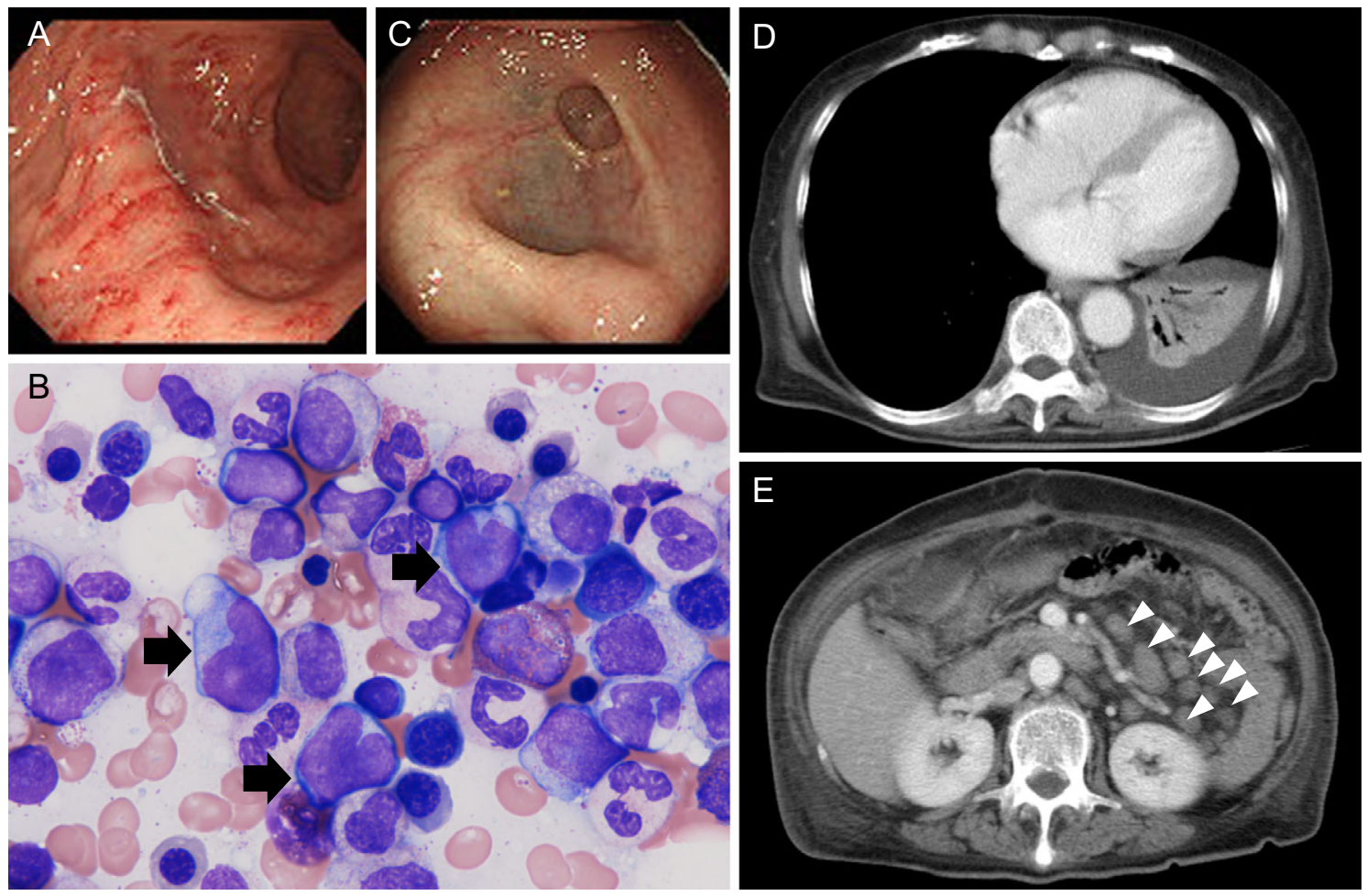

Figure 2. Staging of SMZL. (A) Gastroendoscopy image. Mucosal biopsy revealed lymphoma invasion (data not shown). (B) A bone marrow smear. The black arrows show lymphoma cells. WrightGiemsa staining. Magnification, $\times 1,000$. (C) Colonoscopy image. The mucosae of the sigmoid colon and rectum were mildly opaque. (D) A contrast-enhanced CT scan of the lungs. Pleural effusion and atelectasis of the left lower lung are shown. (E) A contrast-enhanced CT scan of the abdomen. Arrowheads, swollen lymph nodes.

Table 2. Coagulation Data on Referral to the Department of Hematology.

\begin{tabular}{|c|c|c|c|c|c|c|c|}
\hline & & Unit & Range & & & Unit & Range \\
\hline PT sec & 11.8 & $\mathrm{sec}$ & & Factor VIII & 21 & $\%$ & $60-150$ \\
\hline PT \% & 97 & $\%$ & $\geq 70$ & Factor IX & 87 & $\%$ & $70-130$ \\
\hline PT-INR & 1.01 & INR & & vWF:Ag & $\underline{20}$ & $\%$ & $50-155$ \\
\hline APTT & $\underline{40.4}$ & $\mathrm{sec}$ & $24-38$ & vWF:RCo & $\overline{<6}$ & $\%$ & $60-170$ \\
\hline Fibrinogen & 291 & $\mathrm{mg} / \mathrm{dL}$ & $150-350$ & $\mathrm{RCo} / \mathrm{Ag}$ & $<0.3$ & & \\
\hline FDP & $\underline{23}$ & $\mu \mathrm{g} / \mathrm{mL}$ & $0-5$ & \multicolumn{4}{|c|}{ Mixing test (vWF:RCo) } \\
\hline D-dimer & $\underline{4.3}$ & $\mu \mathrm{g} / \mathrm{mL}$ & $0.0-0.9$ & $0 \mathrm{~h}$ & 33 & $\%$ & \\
\hline Lupus anti-coagulant & $\overline{(-)}$ & & Not detectable & $2 \mathrm{~h}$ & 39 & $\%$ & \\
\hline Coagulation inhibitor & $(-)$ & & Not detectable & & & & \\
\hline
\end{tabular}

Underlines show the values outside the reference ranges. PT: prothrombin time, APTT: activated partial thromboplastin time, FDP: fibrin degradation product, vWF:Ag: von Willebrand factor antigen, vWF:RCo: von Willebrand factor activity (ristocetin cofactor test), NA: not available, Sec: second

lymphadenopathy showed mild regression, but thickening of the ileum wall was demonstrated by CT. The bleeding tendency and coagulation data showed no improvement. The patient refused to receive additional chemotherapy and was referred to another hospital.

\section{Discussion}

We herein reported a patient with SMZL and AVWS accompanied by splenic bleeding. Lymphoproliferative disorders, including non-Hodgkin's lymphoma, are the leading cause of AVWS $(6,7)$. The proposed mechanisms of AVWS include selective or non-selective adsorption of VWF on ma- lignant cells, development of autoantibodies against VWF, mechanical destruction of VWF under high shear stress, and increased proteolysis of $\operatorname{VWF}(6,7)$. In the literature, four cases of marginal zone lymphoma associated with AVWS have been described (9-12). Among them, there was only one case report of splenic marginal zone lymphoma accompanied by AVWS (9). The lymphoma cells were positive for CD42 (glycoprotein Ib) and VWF on flow cytometry, suggesting that the adsorption of VWF on lymphoma cells was the cause of AVWS in that case (9). We evaluated the expression of these molecules by immunostaining the frozen splenic tissues. Because the diagnosis of AVWS was made after SMZL was diagnosed, a flow cytometric analysis of 
A

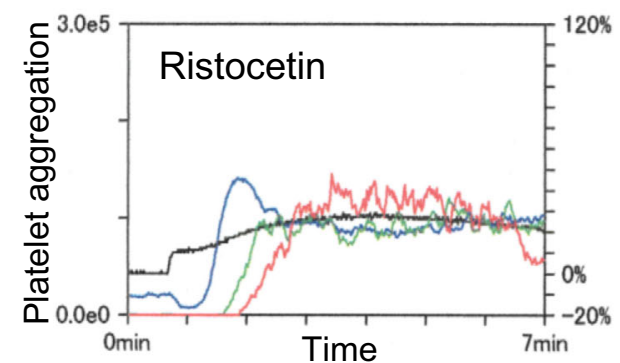

C

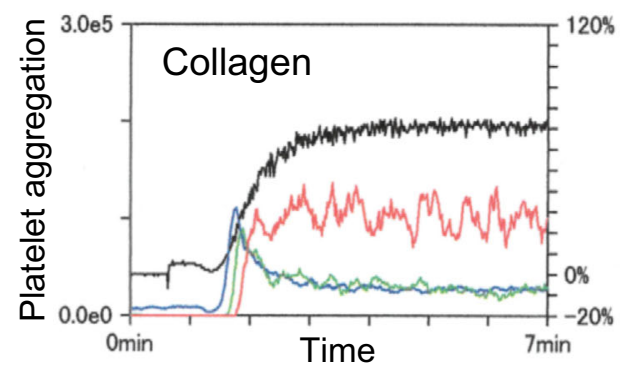

B
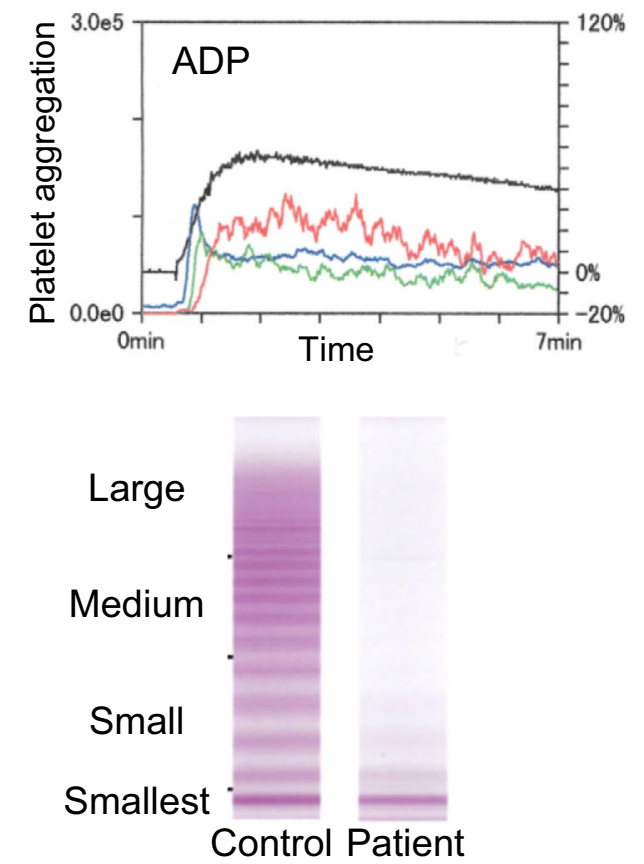

Figure 3. Coagulopathy due to AVWS. (A) - (C) Decreased ristocetin-induced platelet aggregation. Platelet aggregation curves induced by (A) ristocetin, (B) ADP, and (C) collagen are shown. The blue, green, and red lines show platelet aggregation of small, medium, and large size, respectively (left axis). The black line shows the total aggregation (right axis). The aggregation was positive when the total coagulation was higher than $50 \%$. (D) von Willebrand factor multimer assay. The absence of largeand medium-sized multimers is shown.

CD42 and VWF could not be performed. Unlike the previous report (9), the lymphoma cells in the spleen of the present case did not express these molecules, although megakaryocytes and platelets were stained positive in the clot of the BM aspirate (data not shown). Adsorption of VWF on lymphoma cells was thus excluded. Since the previous report did not show the exact figures, it is not clear whether they used appropriate controls (staining with isotype control antibodies, positive and negative controls) to rule out nonspecific binding of the anti-CD42 and anti-VWF antibodies (9). The present case had $\mathrm{IgG}-\kappa \mathrm{M}$ protein. Monoclonal IgG might have caused accelerated clearance of VIII/VWF complex $(6,7)$.

Mildly prolonged APTT was the initial laboratory finding that led to the diagnosis of AVWS in the present case (Table 2). Except for splenic bleeding, the bleeding tendency was mild. A careful examination of bleeding symptoms and abnormal coagulation data in elderly patients might lead to the diagnosis of AVWS and its underlying diseases, including malignancy (13).

The primary treatment of AVWS is that of the underlying disease $(6,7)$. However, AVWS has not always been resolved, even when the treatment of underlying diseases was successful $(12,14)$. In the present case, although SMZL was quite advanced, the patient refused to receive conventional chemotherapy and instead chose rituximab monotherapy. In the literature, rituximab has not been effective in AVWS associated with MGUS (15-17) or with lymphoplasmacytic lymphoma (18), although it has been effective in AVWS as- sociated with B cell lymphoma (MALT lymphoma) (10, 11), monoclonal B cell lymphocytosis (19), essential mixed cryoglobulinemia (20), and $\operatorname{SLE}(21,22)$. Although the lymphadenopathy in our case showed mild shrinkage, the AVWS was not resolved. The bleeding tendency was mild except for splenic bleeding, and no specific medication such as VIII/VWF concentrate or desmopression was administered. Additional chemotherapy using purine analogs or alkylating agents might have improved the outcome $(2,3)$.

SMZL rarely shows lymph node invasion $(1,2)$. Our case had splenomegaly and multiple intraabdominal/paraaortic lymphadenopathies, and invasion to the BM, gastric and intestinal mucosae, and possibly the pleura, which resulted in pleural effusion and partial atelectasis (Fig. 2). We successfully demonstrated that the intraabdominal lymph nodes and spleen contained the same lymphoma cells by PCR amplification and sequencing of CDR-3. Thus, advanced SMZL can involve the lymph nodes and other organs. Appropriate treatment should be provided before progression.

Hematological malignancy is an important differential diagnosis of splenic bleeding with/without rupture $(23,24)$. The proposed mechanisms of spontaneous splenic rupture are: (1) splenomegaly resulting in architectural changes (splenic infarction, increased parenchymal fragility, and altered vascular resistance) and thrombocytopenia due to hypersplenism, (2) infiltration of the splenic capsule by malignant cells, and (3) coagulopathy [anticoagulation therapy or disseminated intravascular coagulation (DIC)] $(24,25)$. There are three reports of non-traumatic spontaneous splenic 
rupture in patients with SMZL. In two cases, there was no obvious trigger to cause the rupture $(25,26)$. The other case was SMZL with transformation and a splenic artery pseudoaneurysm (27). The present case was the first report of SMZL with splenic bleeding associated with AVWS. Intriguingly, AVWS typically presents mucocutaneous bleeding, not bleeding in solid organs $(6,7)$. The huge size of the spleen and AVWS might have triggered splenic bleeding in the present case.

In summary, we herein presented a case of SMZL with AVWS diagnosed via splenic bleeding. A prolonged APTT in elderly patients might suggest a diagnosis of AVWS, and underlying diseases should be investigated.

The authors state that they have no Conflict of Interest (COI).

\section{Acknowledgement}

We thank Tomonori Ushijima (Department of Pathology, JCHO Tokyo Yamate Medical Center) for assisting in the PCR amplification.

\section{References}

1. Swerdlow SH, Campo E, Harris NL, et al. WHO Classification of Tumours of Haematopoietic and Lymphoid Tissues. 4th ed. International Agency for Research on Cancer, Lyon, 2008: 130-139.

2. Mendes LST, Du M, Matutes E, Wotherspoon A. Splenic marginal zone lymphoma: a review of the clinical presentation, pathology, molecular biology, and management. Blood Lymph Cancer 4: 2938, 2014.

3. Kalpadakis C, Pangalis GA, Vassilakopoulos TP, Sachanas S, Angelopoulou MK. Treatment of splenic marginal zone lymphoma: should splenectomy be abandoned? Leuk Lymphoma 55: 1463-1470, 2014.

4. Berndt MC, Metharom P, Andrews RK. Primary haemostasis: newer insights. Haemophilia 20 Suppl 4: 15-22, 2014.

5. Federici AB. Clinical and laboratory diagnosis of VWD. Hematology Am Soc Hematol Educ Program 2014: 524-530, 2014.

6. Tiede A. Diagnosis and treatment of acquired von Willebrand syndrome. Thromb Res 130 Suppl 2: S2-S6, 2012.

7. Franchini M, Lippi G. Acquired von Willebrand syndrome: an update. Am J Hematol 82: 368-375, 2007.

8. Hayashi K, Furukawa K, Takamoto S, Shiku H, Yamada K. Analysis of cell surface molecules on human platelets with monoclonal antibodies. I. Identification of four platelet-specific surface molecules. Acta Haematol 75: 141-146, 1986.

9. Tefferi A, Hanson CA, Kurtin PJ, Katzmann JA, Dalton RJ, Nichols WL. Acquired von Willebrand's disease due to aberrant expression of platelet glycoprotein Ib by marginal zone lymphoma cells. Br J Haematol 96: 850-853, 1997.

10. Iwabuchi T, Kimura Y, Suzuki T, et al. Successful treatment with rituximab in a patient with primary thymic MALT lymphoma complicated with acquired von Willebrand syndrome and Sjögren syndrome. Rinsho Ketsueki 52: 210-215, 2011 (in Japanese, Abstract in English).

11. Biondo F, Matturro A, Santoro C, et al. Remission of acquired von Willebrand syndrome after successful treatment of gastric MALT lymphoma. Haemophilia 18: e34-e35, 2012.

12. Koyama T, Fujimoto K, Shima M. Acquired von Willebrand syndrome associated with Hashimoto's thyroiditis and subcutaneous mucosa-associated lymphoid tissue lymphoma. Intern Med 52: 2661-2663, 2013.

13. Kruse-Jarres R. Acquired bleeding disorders in the elderly. Hematology Am Soc Hematol Educ Program 2015: 231-236, 2015.

14. Slattery W, Rausch D, Saba N. Refractory acquired von Willebrand disease despite successful treatment of the associated lymphoma. Mayo Clin Proc 77: 1391, 2002.

15. Agarwal N, Klix MM, Burns CP. Successful management with intravenous immunoglobulins of acquired von Willebrand disease associated with monoclonal gammopathy of undetermined significance. Ann Intern Med 141: 83-84, 2004.

16. Grimaldi D, Bartolucci P, Gouault-Heilmann M, Martin-Toutain I, Khellaf M, Godeau B. Rituximab failure in a patient with monoclonal gammopathy of undetermined significance (MGUS)associated acquired von Willebrand syndrome. Thromb Haemost 99: 782-783, 2008.

17. Mazoyer E, Fain O, Dhote R, Laurian Y. Is rituximab effective in acquired von Willebrand syndrome? Br J Haematol 144: 967-968, 2009.

18. Mayerhofer M, Haushofer A, Kyrle PA, et al. Mechanisms underlying acquired von Willebrand syndrome associated with an IgM paraprotein. Eur J Clin Invest 39: 833-836, 2009.

19. Kanakry JA, Gladstone DE. Maintaining hemostasis in acquired von Willebrand syndrome: a review of intravenous immunoglobulin and the importance of rituximab dose scheduling. Transfusion 53: 1730-1735, 2013.

20. Pasa S, Altintas A, Cil T, Danis R, Ayyildiz O, Muftuoglu E. A case of essential mixed cryoglobulinemia and associated acquired von-Willebrand disease treated with rituximab. J Thromb Thrombolysis 27: 220-222, 2009.

21. Jimenez AR, Vallejo ES, Cruz MZ, Cruz AC, Miramontes JV, Jara BS. Rituximab effectiveness in a patient with juvenile systemic lupus erythematosus complicated with acquired von Willebrand syndrome. Lupus 22: 1514-1517, 2013.

22. Taveras Alam S, Alexis K, Sridharan A, et al. Acquired von Willebrand's syndrome in systemic lupus erythematosus. Case Rep Hematol 2014: 208597, 2014.

23. Giagounidis AA, Burk M, Meckenstock G, Koch AJ, Schneider W. Pathologic rupture of the spleen in hematologic malignancies: two additional cases. Ann Hematol 73: 297-302, 1996.

24. Adachi K, Arima D, Hosaka A, et al. A non-traumatic splenic rupture leads to diagnosis of underlying abnormality. Lancet $\mathbf{3 8 4}$ : 1820, 2014.

25. Badine E, Richa E, El-Sayah D, Terjanian T. A case report of splenic rupture due to marginal zone lymphoma. Ann Hematol 86: 845-846, 2007.

26. Aldridge MC, Nederstrom C, Swamy R. Splenic marginal cell lymphoma (SMZL): report of its presentation with spontaneous rupture of the spleen. J Surg Case Rep 2013: rjt105, 2013.

27. Huang YC, Xie ZY, Tseng HS, Yang CF, Hsiao LT. Splenic artery pseudoaneurysm with rupture by transformed splenic marginal zone B cell lymphoma. Ann Hematol 89: 639-640, 2010.

The Internal Medicine is an Open Access article distributed under the Creative Commons Attribution-NonCommercial-NoDerivatives 4.0 International License. To view the details of this license, please visit (https://creativecommons.org/licenses/ by-nc-nd/4.0/).

(C) 2017 The Japanese Society of Internal Medicine

http://www.naika.or.jp/imonline/index.html 